\title{
Factors influencing the fate of antibiotic resistance genes during thermochemical pretreatment and anaerobic digestion of pharmaceutical waste sludge
}

Tong, Juan; Lu, Xueting; Zhang, Junya; Angelidaki, Irini; Wei, Yuansong

\section{Published in:}

Environmental Pollution

Link to article, DOI:

10.1016/j.envpol.2018.09.096

Publication date:

2018

Document Version

Peer reviewed version

Link back to DTU Orbit

Citation (APA):

Tong, J., Lu, X., Zhang, J., Angelidaki, I., \& Wei, Y. (2018). Factors influencing the fate of antibiotic resistance genes during thermochemical pretreatment and anaerobic digestion of pharmaceutical waste sludge. Environmental Pollution, 243(Part B.), 1403-1413. https://doi.org/10.1016/j.envpol.2018.09.096

\section{General rights}

Copyright and moral rights for the publications made accessible in the public portal are retained by the authors and/or other copyright owners and it is a condition of accessing publications that users recognise and abide by the legal requirements associated with these rights.

- Users may download and print one copy of any publication from the public portal for the purpose of private study or research.

- You may not further distribute the material or use it for any profit-making activity or commercial gain

- You may freely distribute the URL identifying the publication in the public portal 


\section{Accepted Manuscript}

Factors influencing the fate of antibiotic resistance genes during thermochemical pretreatment and anaerobic digestion of pharmaceutical waste sludge

Juan Tong, Xueting Lu, Junya Zhang, Irini Angelidaki, Yuansong Wei

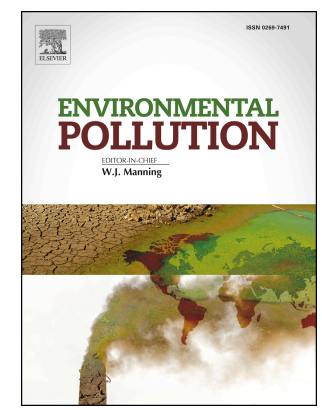

PII: S0269-7491(18)32952-X

DOI: $\quad$ 10.1016/j.envpol.2018.09.096

Reference: ENPO 11638

To appear in: Environmental Pollution

Received Date: 27 June 2018

Revised Date: 17 September 2018

Accepted Date: 19 September 2018

Please cite this article as: Tong, J., Lu, X., Zhang, J., Angelidaki, I., Wei, Y., Factors influencing the fate of antibiotic resistance genes during thermochemical pretreatment and anaerobic digestion of pharmaceutical waste sludge, Environmental Pollution (2018), doi: https://doi.org/10.1016/ j.envpol.2018.09.096.

This is a PDF file of an unedited manuscript that has been accepted for publication. As a service to our customers we are providing this early version of the manuscript. The manuscript will undergo copyediting, typesetting, and review of the resulting proof before it is published in its final form. Please note that during the production process errors may be discovered which could affect the content, and all legal disclaimers that apply to the journal pertain. 


\section{Graphical abstract}

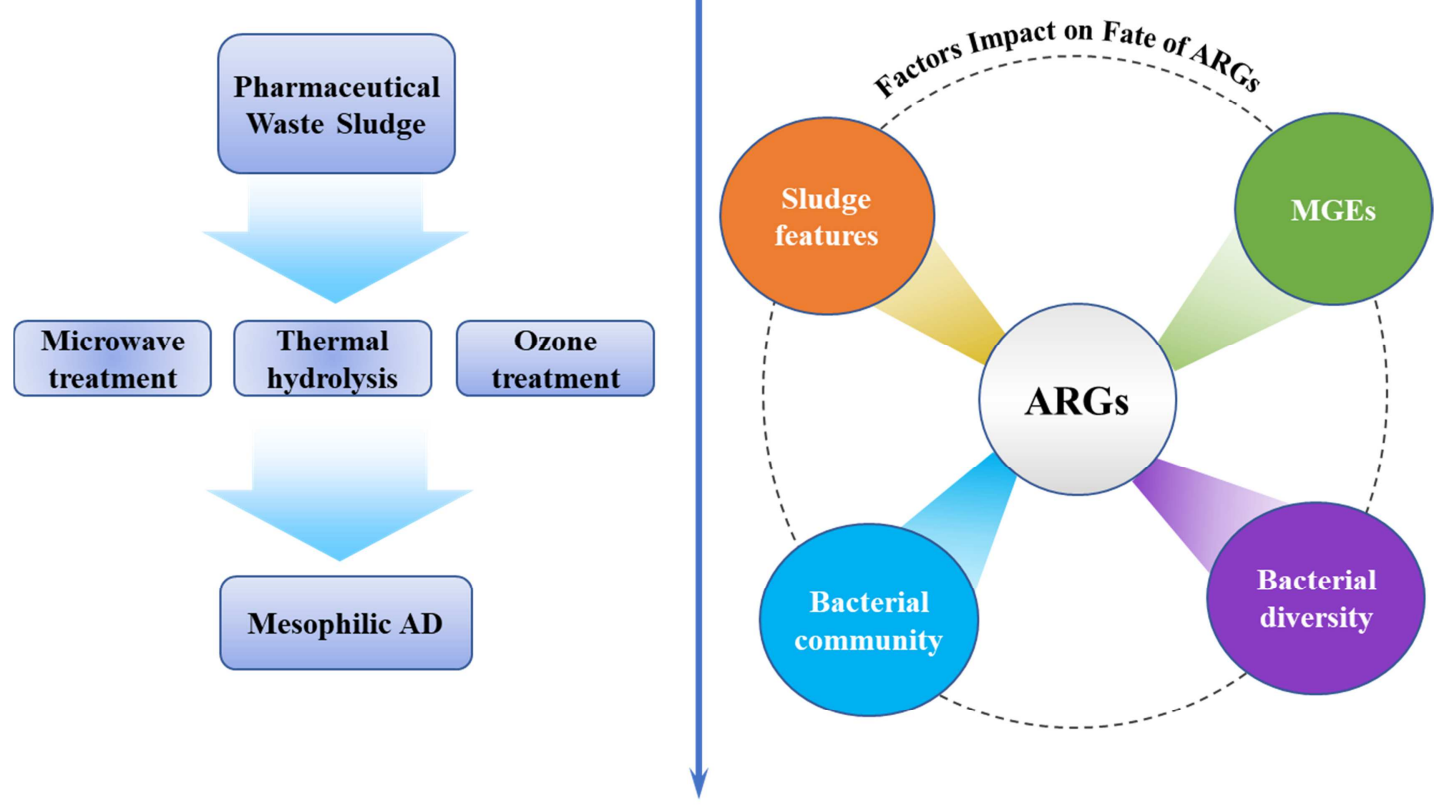




\section{Factors influencing the fate of Antibiotic Resistance Genes}

\section{2 during Thermochemical Pretreatment and Anaerobic Digestion}

3 of Pharmaceutical Waste Sludge

4 Juan Tong ${ }^{1,2} \cdot$ Xueting $\mathrm{Lu}^{2} \cdot$ Junya Zhang $^{1,2} \cdot$ Irini Angelidaki $^{3} \cdot$ Yuansong Wei $^{1,2} *$

5 1. State Key Joint Laboratory of Environmental Simulation and Pollution Control,

6 Research Center for Eco-Environmental Sciences, Chinese Academy of Sciences,

$7 \quad$ Beijing 100085, China

8 2. Department of Water Pollution Control, Research Center for Eco-Environmental

9 Sciences, Chinese Academy of Sciences, Beijing 100085, China

10 3. Department of Environmental Engineering, Technical University of Denmark,

11 Copenhagen Lyngby 2800, Denmark

12 Corresponding Author

13 Yuansong Wei*, Email: yswei@ rcees.ac.cn

14 Juan Tong, Email: hittj@163.com 


\section{Abstract}

The prevalence of antibiotic resistance genes (ARGs) in waste sludge, especially for the pharmaceutical waste sludge, presents great potential risks to human health. Although ARGs and factors affecting their spreading are of major importance for human health, the factors influencing the fate of ARGs during sludge treatment, especially for pharmaceutical sludge treatment are not yet well understood. In order to be able to minimize ARGs spreading, it is important to find what is influencing their spreading. Therefore, certain factors, such as the sludge characteristics, bacterial diversity and community composition, and mobile genetic elements (MGEs) during the advanced AD of pharmaceutical sludge with different pretreatments were studied, and their affinity with ARGs was elucidated by Spearman correlation analysis.

Furthermore, multiple linear regression was introduced to evaluate the importance of the various factors. Results showed that $59.7 \%-88.3 \%$ of the variations in individual ARGs and total ARGs can be explained by the corresponding factors. Bacterial diversity rather than specific bacterial community composition affected the fate of ARGs, whereas alkalinity was the most important factor on ARGs among all sludge characteristics investigated in this study. Besides, $66.4 \%$ of variation of total ARGs was driven by the changes of MGEs. Multiple linear regression models also reveal the collective effect of these factors on ARGs, and the contributions of each factor impact on ARGs. This study provides more comprehension about the factors impact on the fate of ARGs during pharmaceutical sludge treatment, and offers an approach to evaluate the importance of each factor, which method could be introduced for 
evaluation of factors influencing ARGs during other types of sludge or wastewater treatment.

Keywords: antibiotic resistance genes (ARGs); mobile genetic elements (MGEs); bacterial community; sludge characteristics; multiple linear regression

\section{Introduction}

Wastewater treatment plants are important for controlling antibiotic resistance emergence and spreading, as these facilities are central collection points for antibiotic resistant bacteria (ARB), antibiotics, biocides, and heavy metals (Michael et al., 2013; Calero-Caceres and Muniesa, 2016; Manaia et al., 2018). Pharmaceutical wastewaters harbor more $\mathrm{ARB}$ and antibiotic resistance genes (ARGs) than municipal wastewater (Liu et al., 2012; Liu et al., 2014), and therefore require more attention. However, most countries are lack of specific legislation for antibiotic content and regulation disposal of these wastewaters. Therefore, attention is required due to the huge negative health impact could be caused by spreading of antibiotic resistance. Inadequate treatment of waste sludge from pharmaceutical wastewater treatment plants could impose a potential risk for resistance spreading. It is therefore imperative to elucidate the factors influencing the fate of ARGs during sludge treatment for developing effective technologies to control antibiotic resistance spreading. However, the factors that impact ARGs and influence their development are rather complex and remain a black box (Manaia et al., 2018).

8 Wastewater or sludge characteristics and environmental conditions are reported as important factors affecting the spreading of antibiotic resistance. For example, COD 
60

could influence how antibiotics affect ARGs (Guo et al., 2017), and a higher COD

61 loading rate could amplify the growth of all six types of ARB during wastewater

62 treatment (Yuan et al., 2015). Temperature is another important factor influencing ARGs. However, conflicting results with respect to temperature for reducing ARGs are reported. For example, thermophilic AD of waste sludge was found to offer greater and more rapid reduction of ARGs than conventional mesophilic AD (Ghosh et al., 2009; Diehl and LaPara 2010; Burch et al., 2016), while others have found no difference on ARG reduction based on digestion temperature (Ma et al., 2011; Zhang et al., 2015). In addition, $\mathrm{pH}$ can influence ARGs. For example, the potential of tetracycline resistance genes transferred via genetic vectors was greatly promoted in acidic pH conditions (Huang et al., 2016). Alkaline fermentation ( $\mathrm{pH}$ 10) of sludge led to a greater reduction in sul genes and tet genes than fermentation at neutral $\mathrm{pH}$. The shift of ARG hosts range and restricted gene transfer potential at $\mathrm{pH} 10$ might result in a critical effect on the attenuation of ARGs (Huang et al., 2017). It was found that the major reduction of the ARGs occurred at the acidogenic phase (with $\mathrm{pH}$ around 6) of a two-stage thermophilic digestion process, whereas an increase of the ARGs was observed at the subsequent methanogenic phase (Wu et al., 2016). These findings suggest that the influence of sludge characteristics and environmental conditions is complex and often lead to conflicting results. Microbial community composition is important for the fate of ARGs (Miller et al., 2016; Zhang et al., 2016), which could affect the distribution of ARGs in the biosolids after AD of waste sludge (Ma et al., 2011). It was proposed that the variations 
82 observed in ARGs during the $\mathrm{AD}$ of sewage sludge mixed with food waste were mainly linked to bacterial community composition, rather than to the content of mobile genetic elements (MGEs), and heavy metals (Zhang et al., 2016). Changes in the structure of a microbial community may lead to changes in the biodegradation capacity of antibiotics, which likely represents one of the factors underlying the impact of the microbial community on ARGs (Akyol et al., 2016).

Wastewater and sludge contain various MGEs, including plasmids, transposons, integrons and insertion sequences (Guo et al., 2017; An et al., 2018), which are responsible for the horizontal gene transfer (HGT) of resistance genes (Hegstad et al., 2010; Ma et al., 2014). Antibiotic resistance may be amplified from the progressive enrichment of resistant bacteria, and/or transfer of resistance genes between microbial members of a given community (Rizzo et al., 2013). In addition to the above, biocides, heavy metals (Michael et al., 2013), and certain additives, such as zero valent iron (Gao et al., 2016), may also affect the fate of ARGs. All the above suggest that the interactions deciding the fate of ARGs during wastewater and sludge treatment is volatile, complex and remain poorly understood.

The mechanisms determining the fate of ARGs are rather complex, and therefore it still remains unclear which factors are the main drivers on the fate of ARGs. Therefore, this study aims to provide a further understanding of the factors affecting the fate of ARGs during pharmaceutical sludge treatment. In our previous study, the occurrence of ARGs and MGEs in enterococci isolated from sludge, and in genomic DNA during the pharmaceutical waste sludge treated by AD with different 
104 pretreatments were investigated (Tong et al., 2017). Based on this research, sludge

105 characteristics, bacterial community composition, bacterial diversity, MGEs, and their

106 associations with the fate of ARGs were investigated. Additionally, stepwise multiple

107 linear regression analyses were applied to evaluate the importance of sludge

108 characteristics, bacterial community composition, bacterial diversity, and MGEs on

109 the fate of individual ARGs and total ARGs during the pharmaceutical sludge

110 treatment.

\section{2. Materials and methods}

\section{$112 \quad 2.1$ Sludge resources and treatment processes}

113 The sludge used in this study was collected from the sedimentation tank of a

114 wastewater treatment system of a spiramycin production plant in Wuxi, China. The

115 sludge was subjected in a number of treatments (microwave (MW), thermal

116 hydrolysis (TH), and ozone oxidation) and subsequently was treated by anaerobic

117 digestion as described in a previous study (Tong et al., 2017). Figure 1 shows the

118 operation procedure of the sludge treatment. The sludge pretreatment and subsequent

119 AD were repeated three times in independent experiments.

\subsection{Analytical methods for sludge characteristics}

121 The sludge samples were centrifuged at $4000 \mathrm{rpm}$ for $10 \mathrm{~min}$ and filtered through a

$1220.45 \mu \mathrm{m}$ cellulose membrane. The $\mathrm{pH}$, alkalinity (ALK), soluble COD (sCOD)

123 content, protein content, and polysaccharide content of the filtrate was analyzed. The

124 total solid (TS), volatile solid (VS), ALK, and sCOD contents were measured

125 according to the standard methods procedure (APHA, 2005). The $\mathrm{pH}$ was determined 
126 using a pH meter (pHs-3C, Leici, China). The modified Lowry method was adopted

127 to determine the protein content using bovine serum albumin as the protein standard

128 (Frolund et al., 1995). Polysaccharides were measured by the Dubois method with

129 D-glucose as the standard (Dubois et al., 1956).

$130 \quad 2.3$ DNA extraction and quantification

131 One milliliter of the pretreated sludge and $0.5 \mathrm{~mL}$ of raw sludge and digested

132 sludge samples, which volume was optimized for DNA extraction, were centrifuged at

$1338000 \mathrm{rpm}$ for $15 \mathrm{~min}$, and the pellet from each centrifugation was subsampled for

134 DNA extraction. DNA was extracted using the FastDNA Spin Kit for Soil (MP

135 Biomedicals, US) according to the manufacturer's instructions. Triplicate-extracted

136 DNA of each sample was mixed to minimize the potential variations during the DNA

137 extraction process. A NanoDrop 2000 (Thermo Scientific, USA) was used to

138 determine the DNA concentration and purity.

139 The presence of different mechanisms of macrolide-lincosamide-streptogramin

140 (MLS) resistance, i.e. the following genes were investigated: efflux pump genes

141 mefA/E; esterase genes ere A; ribosomal methylase genes erm $\mathrm{B}, \mathrm{F}$ and $\mathrm{X}$; macrolide

142 phosphotransferase genes $m p h \mathrm{~B}$; and the ribosomal protection genes of tetracycline

143 resistance, tet $\mathrm{M}$ and tet $\mathrm{O}$, which were intimately connected with erm $\mathrm{B}$ (Roberts et al.,

144 1999; Tremblay et al., 2011), MGEs (Tn916/1545, ISCR1, and intI1). The 16S rRNA

145 genes were quantified using a Step One Plus real-time PCR system (ABI, USA). The

146 primers and detail quantitative PCR procedure were described in our previous study

147 (Tong et al., 2017). 
148

149

150

151

152

153

154

155

156

157

158

159

160

161

162

163

164

165

166

167

168

169

\subsection{High-throughput sequencing and bacterial community analysis}

High-throughput sequencing was performed as previously described (Zhang et al., 2016). In brief, PCR primers 515F and 806R targeting the V4 region of the $16 \mathrm{~S}$ rRNA gene for both bacteria and archaea. Sequencing was performed with Illumina high-throughput sequencing method (Caporaso et al., 2011). Barcodes unique to each sample were incorporated before the forward primers, which allowed for the identification of each sample in a mixture for an Illumina sequencing run. DNA was amplified in triplicate for each sample. The PCR amplicons were further purified with a DNA purification kit (Gel Purification kits, Sangon, China). The DNA

concentrations were determined using a spectrometer (Qubit 2.0, Invitrogen, USA) Amplicons from different samples were then mixed to achieve equal mass concentrations in the final mixture, which were sent to Sangon Co., Ltd. in Shanghai for small fragment library construction and pair-end sequencing using the Illumina MiSeq sequencing system (Illumina, USA).

Sequencing reads were assigned to each sample according to the unique barcode of each sample. Pairs of reads from the original DNA fragments were first merged using FLASH, and then PRINSEQ was used for the quality control of these merged reads.

The barcode and primers were then removed. All the reads were uploaded to MG-RAST (http://metagenomics.anl.gov/linkin.cgi?project=mgp80384). PCR chimeras were filtered out using UCHIME. After the above filtration, the average length of all clean reads was 250 bp and the average sequencing depth was 44,523 clean reads for the bacterial community analysis. The taxonomic classification of the 
170 sequences was performed using the Ribosomal Database Project (RDP) Classifier at

171 the bootstrap cutoff of $80 \%$ suggested by the RDP.

172

173

174

175

176

177

178

179

180

181

182

183

184

185

186

187

188

189

190

191

\subsection{Data analysis}

The Spearman correlation was performed using SPSS 20.0 (IBM, USA), and a $p$ value $<0.05$ was considered statistically significant. Multiple linear regression analyses (Neter et al., 1996) were performed by SPSS 20.0. Based on F-tests, the least significant variables were removed from the model via a stepwise variable reduction.

To simplify the bacterial community composition in the multiple linear regression model, a dimension reduction for the dominant genera was first conducted based on a PCA using SPSS 20.0. Then, the top 5 master coordinates (Coord1, Coord2, Coord3, Coord4, and Coord5), with a cumulative variance proportion over $80 \%$ were adopted to express the bacterial community (Table S1, S2). A $p$ value $<0.05$ of each model was considered as statistically significant. The adjusted $R^{2}$ values of the linear regression models are indicators of how well the regression model explained the new observations. A principal component analysis (PCA) and Procrustes analysis were conducted using Canoco 5.0 (Microcomputer Power, USA). The Procrustes analysis was done by rotating the coordinate of changes of the bacterial community to match the profiles of ARGs based on a PCoA analysis (Lou et al., 2017). The values of explanatory variables accounted for the sludge treatment process showed how much evolution of ARGs could be explained the bacterial community succession during the sludge treatment. The heatmap illustrating the evolution of the quantified genes in each sample was built by Heml 1.0. 
192

193

194

195

196

197

198

199

200

201

202

203

204

205

206 211 produced by the degradation of protein and nitrogenous compounds during AD (Song 212 et al., 2004).

\section{Results and discussion}

\subsection{Variations in sludge characteristics}

The variations in sludge characteristics during sludge treatment are shown in Figure 2. The TS increased by $4.9 \%$ and $5.1 \%$ for the MW and ozone pretreatments because of evaporation, whereas the TS was reduced by $29.2 \%$ after the TH pretreatment because of dilution by the condensed process steam. The same trend was observed for the VS during the pretreatments. The TH pretreatment showed the highest release of soluble organics, with concentrations which were 15.0, 29.3, and 39.8 times higher compared to raw sludge for the SCOD, protein, and polysaccharide, respectively. The second best pretreatment for sludge was the MW (15.0, 29.8, and 32.3 times higher, respectively). The ozone pretreatment resulted in the lowest soluble organics release (6.5 times of sCOD). The AD with TH pretreatment presented the best VS reduction (39.3\% reduction), which was followed by AD with the MW (26.4\% VS reduction) and ozone pretreatments (25.0\% VS reduction).

The initial $\mathrm{pH}$ of pharmaceutical sludge was 7.65, with $0.08 \sim 0.48$ variations of $\mathrm{pH}$ after pretreatments. The $\mathrm{pH}$ of digested sludge ranged from 7.47 7.62, which was typical for normal AD. The ALK increased from $78.9 \%$ to $230.1 \%$ during AD, which variation trend was consistent with the results of the previous study (Zou et al., 2013).

The increasing ALK after AD was mainly caused by the increasing ammonia

\subsection{Variations in bacterial diversity}


214 Microbial biomass on basis of 16S rRNA, was reduced after the sludge

215 pretreatment but increased during the subsequent AD (Figure 3). However, the

216 bacterial diversity did not always show the same trends. The Chao 1 index, which

217 represents the richness of microbial diversity; Pielou index, which expresses the

218 evenness of microbial diversity; and Shannon index, which is considering both

219 richness and evenness of microbial diversity were investigated in the present study.

220 During the sludge pretreatment, the Shannon index was reduced from 5.00 for the raw

221 sludge to 4.59, 2.63, and 4.69 for the MW-, TH-, and ozone-pretreated sludge,

222 respectively; and $31.1 \%, 66.6 \%$ and $21.9 \%$ reduction for Chao 1 index. In addition,

223 Pielou index decreased from 0.64 to $0.60,0.39$, and 0.61 . The $16 \mathrm{~S}$ rRNA decreased

224 from 12.7 to $12.7,11.7$, and $12.5 \mathrm{log}$ copies $\cdot \mathrm{g}^{-1}$, respectively. The radiation by MW

225 treatment, heating and increased pressure of the TH treatment, and oxidation of the

226 ozone treatment did not only reduce the microbial biomass, but also the microbial

227 diversity (both in richness and evenness), indicating that the pretreatments were

228 affecting the various taxa differently. The TH pretreatment showed the best reduction

229 in microbial diversity, with $66.6 \%, 47.5 \%$, and $39.4 \%$ reduction for Chao1, Shannon,

230 and Pielou index, respectively. This result is in agreement with a previous study

231 showing that TH pretreatment for waste sludge could lead to a reduction of microbial

232 diversity (Ma et al., 2011).

233 The Chao1, Pielou, and Shannon index increased simultaneously both in the AD

234 without pretreatment and AD with MW pretreatment, indicating the microbial

235 diversity both in richness and evenness increased along with the biomass. However, 
236 all these three diversity indexes decreased by $4.7 \%$ 10.0\% after $\mathrm{AD}$ with $\mathrm{TH}$

237 pretreatment, showing that the microbial diversity reduced even when the biomass

238 increased (with $2.3 \%$ increase) after $\mathrm{AD}$, and that the $\mathrm{TH}$ was the harshest treatment

239 permitting recovery of only few microorganisms during the AD process. Therefore, it

240 can be concluded that sludge treated by TH has a lower microbial diversity which

241 might affect the subsequent AD process.

\section{$242 \quad 3.3$ Bacterial community succession}

243 The bacterial community succession during the sludge treatments is shown in

244 Figure 4. To simplify the results, the top 10 abundant phyla and top 10 abundant

245 genera in each sample (23 abundant phyla and 61 abundant genera (the genera names

246 shown in Table S3) were obtained from 36 samples) were selected for comparison.

247 The top three dominant phyla were Proteobacteria (57.2\%), Bacteroidetes (18.0\%),

248 and Planctomycetes (7.2\%) for the spiramycin waste sludge, followed by

249 Verrucomicrobia (3.7\%) and Acidobacteria (3.3\%) (Figure 4a). Likewise,

250 Proteobacteria and Bacteroidetes were found dominant phyla in sewage sludge

251 (Zhang et al., 2012; Zhang et al., 2016). However, Firmicutes and Actinobacteria were

252 also found to be dominant phyla in sewage sludge which was not the case for the

253 spiramycin waste sludge. These differences were also observed in the sludge after AD,

254 with Proteobacteria, Bacteroidetes, Firmicutes, and Cloacimonetes the dominant

255 phyla in this study, whereas Proteobacteria, Firmicutes, Bacteroidetes, and

256 Chloroflexi were the dominant phyla in sewage sludge after mesophilic digestion

257 (Bibby et al., 2010). It seems that the different sludge sources (sewage sludge $v s$. 
258 pharmaceutical sludge) supported the development of different microbial

259 communities.

260 For the TH-pretreated sludge, the abundance of Proteobacteria increased from 57.2\%

261 to $82.3 \%$, indicating their robustness to TH conditions. On the contrary, the

262 abundance of Bacteroidetes decreased from $18.0 \%$ to 7.4\%, and Proteobacteria,

263 Bacteroidetes, and Firmicutes became the dominant phyla. The abundance of

264 Firmicutes increased after the pretreatments (from $2.1 \%$ to $6.2 \%, 6.9 \%$, and $5.0 \%$,

265 respectively, for the control to $\mathrm{MW}, \mathrm{TH}$, and ozone pretreatments). Many Firmicutes

266 produce endospores and therefore can survive extreme conditions, such as heat,

267 desiccation, UV irradiation, and the presence of organic solvents and oxidizing agents

268 (Galperin, 2013). Firmicutes are well-known to be acetogenic and syntrophic bacteria

269 that can degrade VFA (Yi, et al, 2014). The increase of Firmicutes in the sludge could

270 generate a favorable environment for fermentation (Ma et al., 2011), provides

271 precursors for methanogenesis, and therefore plays a critical role in anaerobic

272 digestion (Yi, et al, 2014). The augmentation of Firmicutes after pretreatments in this

273 study might be an important reason for the higher methane production in the AD

274 sludge with pretreatments.

275 At the genus level (Figure 4b), the abundance of genera belonging to Proteobacteria

276 (i.e. Pseudomonas, Acinetobacter, and Alcaligenes, etc.) Firmicutes (such as

277 Clostridium) increased or remained the same after the sludge pretreatments.

278 Acinetobacter and Pseudomonas are opportunistic pathogenic genera in the

279 Proteobacteria group. The abundance of Pseudomonas increased after all 
280 pretreatments, especially the $\mathrm{TH}$ pretreatment (from $0.1 \%$ to $38.7 \%$ ), whereas the

281 abundance of Acinetobacter increased from $0 \%$ to $5.0 \%$ in TH-pretreated sludge but

282 was 0-0.1\% in other pretreated sludge. Pseudomonas, Alcaligenes, and Clostridium

283 are acidogenic fermentation genera (Li et al., 2011). Alcaligenes might greatly

284 contribute to the degradation of VFAs and stabilization of ammonium level in the

285 anaerobic digester (Shoda and Ishikawa, 2014; Wu et al., 2016). Clostridium can

286 produce cellulases that hydrolyze cellulosic biomass, and also contribute to acetate,

287 propionate and butyrate fermentation (Li et al., 2011). Cooperation among these

288 microorganisms playing their respective roles in one or more trophic levels including

289 hydrolysis, fermentation, and acetogenesis is needed for mineralization of organic

290 matter to biogas (Yi, et al, 2014). Therefore, the prevalence of the above fermentation

291 genera could benefit for methane production. However, the abundance of Zoogloea,

292 Thiobacillus, and Lewinella reduced after the sludge pretreatments. Zoogloea is an

293 aerobic chemoorganotrophic bacterium responsible for forming zoogloeas and is

294 common in activated sludge (Shin et al., 1993). Thiobacillus includes obligate aerobes

295 and facultative denitrifying types (Kelly and Wood 2000). Lewinella is also aerobic,

296 and it cannot grow at temperatures above $35^{\circ} \mathrm{C}$ (Khan et al., 2007). The bacterial

297 diversity in Chao 1, Shannon, and Pielou index of the digested sludge was

$2984.3 \% \sim 181.3 \%$ higher than that of the pretreated sludge (Figure 3), resulted in complex

299 variations in the bacterial community in the genus level during the AD stage.

300 Principal component analysis (PCA) showed that sludge pretreatments

301 significantly changed the bacterial community composition of sludge (Figure 5). The 
302 greatest dissimilarity in bacterial community composition was between $\mathrm{TH}$ pretreated

303 and raw sludge. There were moderate changes of bacterial community composition

304 after MW pretreatment, followed by ozone pretreatment. Likewise, AD significantly

305 changed the microbial composition of sludge. The bacterial communities of the

306 digested sludge from AD with MW and ozone pretreatments were similar to but

307 different from those of the digested sludge from AD with $\mathrm{TH}$ pretreatment. These

308 results indicate that compared with the other two pretreatments, $\mathrm{TH}$ pretreatment

309 caused more radical changes in the bacterial community and this change could

310 influence the bacterial community of the subsequent $\mathrm{AD}$ process.

\section{$311 \quad 3.4$ Variations of ARGs during sludge treatment}

312 The removal of ARGs and MGEs during sludge treatment are shown in Figure 6

313 (the distribution of ARGs and MGEs during sludge treatment seen in our previous

314 study (Tong et al., 2017)). Most of the individual ARGs were reduced after

315 pretreatments but increased after AD. The tendency of ARGs decreasing during

316 pretreatment but enriching after the subsequent $\mathrm{AD}$ is consistent with previous studies

317 dealing with pretreatment and AD of sewage sludge (Ma et al., 2011; Pei et al., 2016;

318 Tong et al., 2016). It is interesting that the increases or reduction of ere A, mefA/E,

319 tet $\mathrm{M}$, tet $\mathrm{O}, m p h \mathrm{~B}$, and $\mathrm{Tn} 916 / 1545$ in Figure 6 were more significant for the AD with

320 pretreatment than that of the $\mathrm{AD}$ without pretreatment. For example, there was

$321 \quad 1.21 \sim 2.02 \log$ copies $\cdot \mathrm{g}^{-1}$ increase for $m e f \mathrm{~A} / \mathrm{E}$ during $\mathrm{AD}$ with pretreatments, but 0.27

$322 \log$ copies $\cdot \mathrm{g}^{-1}$ increase for it during $\mathrm{AD}$ without pretreatment. These results indicate

323 that the sludge pretreatments affect the final output of the individual ARGs after AD 
324 process.

325

340 The increase of ALK during AD were mainly caused by the increasing ammonia

341 produced by the degradation of protein and nitrogenous compounds (Song et al.,

342 2004). Ammonia could inhibit the biodegradation of erythromycin during wastewater

343 treatment (Fan and He, 2011), which means reduction of selective pressure of

344 antibiotics to the ambient bacteria was inhibited. Furthermore, it was found that

345 abundant ammonia could promote horizontal gene transfer (HGT) during wastewater 
346 treatment through conjugative transfer mechanisms (Guo et al., 2015). It can be

347 argued that the host bacteria of $m e f \mathrm{~A} / \mathrm{E}$ and tet $\mathrm{M}$ might be favorite to ALK or

348 ammonia. Therefore, there might be more chances for some specific host bacteria of

$349 m e f \mathrm{~A} / \mathrm{E}$ and tet $\mathrm{M}$ to proliferate during sludge treatment, or more chances for the HGT

350 of $m e f \mathrm{~A} / \mathrm{E}$, tet $\mathrm{M}$ under higher ALK condition. Further study is needed to provide

351 more understanding about the mechanism behind these observations.

352 The relative abundances of MGEs showed significant correlations with ARGs in

353 our previous study (Tong et al., 2017). In this study, the absolute abundances, i.e. the

354 copy number of erm B and ermX all showed statistically significant correlations with

355 intI1, ISCR1, and $\operatorname{Tn} 916 / 1545(p=0.007 \sim 0.033)$. In addition, there was a positive

356 correlation between ere A and ISCRI ( $p=0.002)$, and between tet $\mathrm{O}$ and $\operatorname{Tn} 916 / 1545$

$357(p=0.042)$. The tet $\mathrm{M}$ gene is usually carried by the transposon $\operatorname{Tn} 916$ or a related

358 conjugative transposon. Moreover, a tet $\mathrm{O}$ gene integrated into a transposon carrying

359 the macrolide resistance genes mefA and $m s r \mathrm{D}$ was reported (Roberts, 2005). The

360 transposon $\mathrm{Tn} 916 / 1545$-family containing tet $\mathrm{M}$ and erm $\mathrm{B}$ was also found in

361 enterococci (Hegstad et al., 2010). The transposons that can carry specific resistance

362 genes could contribute to multi-resistance of tetracyclines and macrolides. The

363 affinity of MGEs and ARGs confirmed by the present study is supporting that MGEs

364 is a key factor determining the fates of ARGs during sludge treatment.

365 Among all pretreated sludge, the TH pretreated sludge presented the lowest

366 microbial diversity richness (Chao 1 index $=1925)$. Likewise, thermally hydrolyzed

367 digested sludge showed the lowest microbial diversity richness (Chao 1 index $=5417$ ) 
compared with other digested sludge. A narrow host range for ARGs of TH pretreated sludge, expressed as a relatively low diversity index, would contribute to increased ARGs removal efficiency. This result is consistent with the previous study which proposed that lower bacterial diversity could provide a narrower host range for ARGs and result in fewer ARGs after the sludge treatment (Ma et al., 2011).

The correlation of variations of the abundance of 61 dominated genera and ARGs were also analyzed (Table 1). The hosts of $m p h \mathrm{~B}$ were reported only as Streptococcus and Escherichia according to Antibiotic Resistance Genes Database (ARDB).

However, the genera of Brevundimonas, Longilinea, Smithella, etc. might affect the fate of $m p h$ B. Moreover, Crocinitomix and Simplicispira showed a positive correlation with ereA. It is indicated that these genera might affect the distribution of the corresponding ARGs and should be given more attention in future research. To better explain the impact of succession of bacterial community on ARGs, a Procrustes analysis was conducted (Figure 7). Procrustes analysis could provide the overall correlations between ARGs and the microbial community composition in the reactors (Zhang et al., 2016; Luo et al., 2017). The correlation coefficients between the first two principal axes were 0.80 and 0.62 , respectively. The explanatory variables of bacterial community succession accounted for $43.8 \%$, indicating $43.8 \%$ of the evolution of ARGs in the sludge pretreatment and AD could be explained by the changes of bacterial community. These results suggest that bacterial community composition might play an important role on the fate of ARGs during the sludge treatment, which was consistent with the results from previous reports (Luo et al., 
2017; Zhang et al., 2018).

\subsection{Comprehensive evaluation of factors influencing the fate of ARGs}

For evaluating the factors impacting the fate of ARGs, multiple linear regression analyses were applied, which can be used to explore the importance of various explanatory variables, i.e. various factors. (Czekalski et al., 2015; Herrig et al., 2015, Mao et al., 2015). The effects of bacterial community composition (in genera level), bacterial diversity (Chao 1, Pielou, and Shannon index), MGEs (intI1, ISCR1, and Tn916/1545), and sludge characteristics (polysaccharide, protein, sCOD, pH, and ALK) on the absolute abundances of ARGs during the sludge treatments were analyzed.

The multiple linear regression models are shown in Table 2. The results showed that the models were highly significant for individual ARGs and total ARGs with $p$ values range from 0.000 to 0.002 , indicating linear relationships are not rejected. The adjusted $R^{2}$ values of the linear regression models ranged from 0.597-0.883, which suggests that $59.7 \%-88.3 \%$ of the variations in individual ARGs and total ARGs can be explained by the corresponding factors. According to the multiple linear regression models, $76.3 \%, 50.3 \%$, and $59.7 \%$ variations of $e r m \mathrm{~B}, e r m \mathrm{X}$, and $m p h \mathrm{~B}$ can be explained by the MGEs respectively, whereas the explanatory variables of bacterial diversity account for $78.8 \%$ and $80.0 \%$ of fates of ere A and ermF. Besides, the alkalinity explained $60.3 \%, 82.6 \%$, and $27.5 \%$ of evolutions of mefA/E, tet $\mathrm{M}$, and tet $\mathrm{O}$. There were $66.4 \%$ of the variations in total ARGs can be explained by the changes of MGEs. These results indicate that bacterial diversity rather than bacterial 
412 community composition affected the fate of ARGs, whereas alkalinity was the most

413 important factor on ARGs among all sludge features investigated in this study. ALK in

414 an AD reactor is mainly determined by the concentrations of VFA and ammonia,

415 which are formed as a result of microbial activity in the reactor. In turn, bacteria could

416 affect the fates of ARGs. Therefore, it seems that there is an indirect correlation

417 between ALK and ARGs, which still need further investigation in the future.

418 Moreover, the models also showed these factors affecting the fate of ARGs in a

419 collaborative way. For example, $50.3 \%$ of the variation of ermX could be explained

420 by the drive of MGEs (intI1), with $28.4 \%$ of it contributed by the change of bacterial

421 diversity (Pielou index), and $7.1 \%$ for the change of bacterial community composition

422 (coord4). The evolution of bacterial community composition led to the change

423 of potential host bacteria range of ARGs and MGEs, resulting in different fate of

424 ARGs. Moreover, the lower bacterial diversity might narrow the host range of ARGs

425 and MGEs and then led to changes of ARGs (Ma et al., 2011).

426 Bacterial community shifts rather than MGEs have been reported as the major

427 driver shaping antibiotic resistomes analyzed by partial Redundancy analysis (RDA)

428 (Chen et al., 2016; Zhang et al., 2016; Zheng et al., 2017). The Partial RDA can

429 assess the importance of 3 groups of factors, such as MGEs, bacterial community

430 composition, and sludge characteristics, on the fate of ARGs. However, there are

431 numerous factors contribute to the variations of ARGs, mostly in a complex interplay

432 (Manaia et al., 2018). Based on multiple linear regression models, the MGEs might be

433 the main driver on the fates of total ARGs. It can be argued that the following factors 
434 might result in different main driver for the fate of ARGs: 1) the major influence

435 factors for different ARGs were varied, 2) the composition of total ARGs and MGEs

436 investigated in different studies were not the same, 3) the different level of bacterial

437 community (phyla, genera, etc.) used during the analysis could lead to different 438 results.

\section{Conclusions}

440 Pharmaceutical sludge harbors large amounts of ARGs with a potential risk for

441 resistance spreading, which needs more information about the factors impact on

442 ARGs during pharmaceutical sludge treatment. This study elucidates the factors

443 having impact on the fate of ARGs during pharmaceutical sludge treatment. Each

444 factor was evaluated for its impact on ARGs. Spearman correlation analysis showed

445 the fate of ARGs presented significant correlations with the changes of sludge features,

446 bacterial diversity, bacterial community composition, and MGEs during sludge

447 treatment. Further evaluation with multiple linear regression models showed that

$44859.7 \%-88.3 \%$ of the variations in individual ARGs and total ARGs can be explained

449 by the corresponding factors. And bacterial diversity rather than bacterial community

450 composition affected the fate of ARGs, whereas alkalinity was the most important

451 factor among the sludge characteristics on ARGs. Besides, $66.4 \%$ of the variation of

452 total ARGs was driven by the change of MGEs. Multiple linear regression models

453 also revealed the collective effect of these factors on ARGs, and how much

454 contribution of each factor impact on ARGs. This study provides more comprehension

455 about the factors impact on the fate of ARGs during pharmaceutical sludge treatment, 
456 and the methodology applied in this study could be used for evaluation of other types

457 of sludge or wastewater treatment.

458 Appendix A. Supplementary data

459 Supplementary data related to this article can be found at the online version.

460 Acknowledgments

461 This work was supported by the National Natural Science Foundation of China (No.

462 51578535), the National Major Science \& Technology Projects for Water Pollution

463 Control and Management of China (2015ZX07203-005), and a China Scholarship

464 Council (CSC) scholarship.

465 References

466 APHA, 2005. Standard Methods for the Examination of Water and Wastewater, 21st

467 ed. American Public Health Association, American Water Works Association, $468 \quad$ Washington D.C., USA.

469 Akyol, Ç., Aydin, S., Ince, O. and Ince, B., 2016. A comprehensive microbial insight 470 into single-stage and two-stage anaerobic digestion of oxytetracycline-medicated 471 cattle manure. Chem. Eng. J. 303: 675-684.

472 An, X. L., Chen, Q. L., Zhu, D., Zhu, Y. G., Gillings, M. R. and Su, J. Q., 2018. 473 Impact of wastewater treatment on the prevalence of integrons and genetic 474 diversity of integron gene cassettes. Appl. Environ. Microb. Doi:10.1128/AEM.02766-17.

476 Bibby, K., Viau, E. and Peccia, J., 2010. Pyrosequencing of the 16S rRNA gene to 477 reveal bacterial pathogen diversity in biosolids. Water Res. 44(14): 4252-4260. 
478 Breazeal, M. V., Novak, J. T., Vikesland, P. J. and Pruden, A., 2013. Effect of 479 wastewater colloids on membrane removal of antibiotic resistance genes. Water $480 \quad$ Res. 47(1): 130-140.

Burch, T. R., Sadowsky, M. J. and LaPara, T. M., 2016. Modeling the fate of antibiotic resistance genes and class 1 integrons during thermophilic anaerobic digestion of municipal wastewater solids. Appl. Microbiol. Biotechnol. 100(3): 1437-1444.

Calero-Caceres, W. and Muniesa, M., 2016. Persistence of naturally occurring antibiotic resistance genes in the bacteria and bacteriophage fractions of wastewater. Water Res. 95: 11-18.

Caporaso, J. G., Lauber, C. L., Walters, W. A., Berg-Lyons, D., Lozupone, C. A., diversity at a depth of millions of sequences per sample. P Natl Acad Sci USA.

Castiglioni, S., Bagnati, R., Fanelli, R., Pomati, F., Calamari, D. and Zuccato, E., 2006. Removal of pharmaceuticals in sewage treatment plants in Italy. Environ. Sci. Technol. 40(1): 357-363.

Chen, Q. L., An, X. L., Li, H., Su, J. Q., Ma, Y. B. and Zhu, Y. G., 2016. Long-term field application of sewage sludge increases the abundance of antibiotic resistance genes in soil. Environ. Int. 92-93: 1-10.

497 Czekalski, N., Sigdel, R., Birtel, J., Matthews, B. and Burgmann, H., 2015. Does human activity impact the natural antibiotic resistance background? Abundance of antibiotic resistance genes in 21 Swiss lakes. Environ. Int. 81: 45-55. 
500 Diehl, D. L. and LaPara, T. M., 2010. Effect of temperature on the fate of genes

501 encoding tetracycline resistance and the integrase of Class 1 Integrons within 502 anaerobic and aerobic digesters treating municipal wastewater solids. Environ. $503 \quad$ Sci. Technol. 44(23): 9128-9133.

504 Dubois, M., Gilles, K. A., Hamilton, J. K., Rebers, P. A. and Smith, F., 1956. 505 Colorimetric method for determination of sugars and related substances. Anal. $506 \quad$ Chem. 28(3): 350-356.

507 Frolund, B., Griebe, T. and Nielsen, P. H., 1995. Enzymatic-Activity in the 508 Activated-Sludge Floc Matrix. Appl. Microbiol. Biotechnol. 43(4): 755-761.

509 Galperin, M. Y., 2013. Genome diversity of spore-forming firmicutes. Microbiol. 510 Spectr. 1(2): TBS-0015-2012.

511 Gao, P., Gu, C., Wei, X., Li, X., Chen, H., Jia, H., Liu, Z., Xue, G. and Ma, C., 2016. 512 The role of zero valent iron on the fate of tetracycline resistance genes and class 1 integrons during thermophilic anaerobic co-digestion of waste sludge and kitchen waste. Water Res. 111: 92-99.

515 Ghosh, S., Ramsden, S. J. and LaPara, T. M., 2009. The role of anaerobic digestion in controlling the release of tetracycline resistance genes and class 1 integrons from municipal wastewater treatment plants. Appl. Microbiol. Biotechnol. 84(4):

519 Gonzalez, d. 1. H., M. J. and Vincent, U., 2005. Analysis of macrolide antibiotics by liquid chromatography. J. Pharm. Biomed. Anal. 39(3-4): 376-398.

521 Guo, J., Li, J., Chen, H., Bond, P. L. and Yuan, Z., 2017. Metagenomic analysis 
reveals wastewater treatment plants as hotspots of antibiotic resistance genes and mobile genetic elements. Water Res. 123: 468-478.

524 Guo, X., Pang, W., Dou, C. and Yin, D., 2017. Sulfamethoxazole and COD increase abundance of sulfonamide resistance genes and change bacterial community structures within sequencing batch reactor. Chemosphere. 175: 21-27.

Hegstad, K., Mikalsen, T., Coque, T. M., Werner, G. and Sundsfjord, A., 2010. Mobile 16(6): 541-554.

Herrig, I. M., Boer, S. I., Brennholt, N. and Manz, W., 2015. Development of multiple genetic elements and their contribution to the emergence of antimicrobial resistant Enterococcus faecalis and Enterococcus faecium. Clin. Microbiol. Infect. tetracycline resistance genes in anaerobic treatment of waste sludge: The role of $\mathrm{pH}$ in regulating tetracycline resistant bacteria and horizontal gene transfer. Bioresour. Technol. 218: 1284-1289. the newly designated genera Acidithiobacillus gen. nov., Halothiobacillus gen. nov and Thermithiobacillus gen. nov. Int. J. Syst. Evol. Microbiol. 50: 511-516. 
544 Khan, S. T., Fukunaga, Y., Nakagawa, Y. and Harayama, S., 2007. Emended 545 descriptions of the genus Lewinella and of Lewinella cohaerens, Lewinella $546 \quad$ nigricans and Lewinella persica, and description of Lewinella lutea sp. nov. and 547 Lewinella marina sp. nov. Int. J. Syst. Evol. Microbiol. 57(Pt 12): 2946-2951.

548 Li, Y. B., Park, S. Y. and Zhu, J. Y., 2011. Solid-state anaerobic digestion for methane 549 production from organic waste. Renew Sust. Energ. Rev. 15(1): 821-826.

550 Liu, M., Ding, R., Zhang, Y., Gao, Y., Tian, Z., Zhang, T., and Yang, M., 2014. 551 Abundance and distribution of Macrolide-Lincosamide-Streptogramin resistance 552 genes in an anaerobic-aerobic system treating spiramycin production wastewater. $553 \quad$ Water Res. 63: 33-41.

554 Liu, M., Zhang, Y., Yang, M., Tian, Z., Ren, L., and Zhang, S., 2012. Abundance and 555 46(14): 7551-7557.

558 Luo, G., Li B., Li, L. G., Zhang, T., and Angelidaki I., 2017. Antibiotic Resistance 559 Genes and Correlations with Microbial Community and Metal Resistance Genes 560 in Full-Scale Biogas Reactors As Revealed by Metagenomic Analysis. Environ. $561 \quad$ Sci. Technol. 51(7): 4069-4080.

562 Ma, L. P., Li, B. and Zhang, T., 2014. Abundant rifampin resistance genes and 563 significant correlations of antibiotic resistance genes and plasmids in various 564 environments revealed by metagenomic analysis. Appl. Microbiol. Biotechnol. $565 \quad 98(11): 5195-5204$. 
566 Ma, Y., Wilson, C. A., Novak, J. T., Riffat, R., Aynur, S., Murthy, S. and Pruden, A.,

567 2011. Effect of various sludge digestion conditions on sulfonamide, macrolide,

568 and tetracycline resistance genes and class 1 integrons. Environ. Sci. Technol. $569 \quad 45(18): 7855-7861$.

570 Manaia, C. M., Rocha, J., Scaccia, N., Marano, R., Radu, E., Biancullo, F., Cerqueira,

571 F., Fortunato, G., Iakovides, I. C., Zammit, I., Kampouris, I., Vaz-Moreira, I. and 572 Nunes, O. C., 2018. Antibiotic resistance in wastewater treatment plants: Tackling 573 the black box. Environ. Int. 115: 312-324.

574 Mao, D., Yu, S., Rysz, M., Luo, Y., Yang, F., Li, F., Hou, J., Mu, Q. and Alvarez, P. J., 575 2015. Prevalence and proliferation of antibiotic resistance genes in two municipal wastewater treatment plants. Water Res. 85: 458-466.

577 Michael, I., Rizzo, L., McArdell, C. S., Manaia, C. M., Merlin, C., Schwartz, T., 578 Dagot, C. and Fatta-Kassinos, D., 2013. Urban wastewater treatment plants as 579 hotspots for the release of antibiotics in the environment: A review. Water Res. 580 47(3): 957-995.

581 Miller, J. H., Novak, J. T., Knocke, W. R. and Pruden, A., 2016. Survival of antibiotic 582 resistant bacteria and horizontal gene transfer control antibiotic resistance gene content in anaerobic digesters. Front. Microbiol. 7(263).

584 Neter, J., Kutner, M. H., and Nachtsheim, C. J., Applied Linear Statistical Models. Vol. 4. 1996: Irwin Chicago.

Pei, J., Yao, H., Wang, H., Ren, J. and Yu, X., 2016. Comparison of ozone and thermal hydrolysis combined with anaerobic digestion for municipal and pharmaceutical 
Rizzo, L., Manaia, C., Merlin, C., Schwartz, T., Dagot, C., Ploy, M. C., Michael, I. and Fatta-Kassinos, D., 2013. Urban wastewater treatment plants as hotspots for antibiotic resistant bacteria and genes spread into the environment: A review. Sci. Total Environ. 447: 345-360.

Roberts, M. C., 2005. Update on acquired tetracycline resistance genes. FEMS Microbiol. Lett. 245(2): 195-203.

Roberts, M. C., Sutcliffe, J., Courvalin, P., Jensen, L. B., Rood, J. and Seppala, H., 1999. Nomenclature for macrolide and macrolide-lincosamide-streptogramin B resistance determinants. Antimicrob. Agents Ch. 43(12): 2823-2830.

Rubinstein, E. and Keller, N., 1998. Spiramycin renaissance. J. Antimicrob. Chemother. 42(5): 572-576.

Shin, Y. K., Hiraishi, A. and Sugiyama, J., 1993. Molecular Systematics of the Genus Zoogloea and Emendation of the Genus. Int. J. Syst. Evol. Microbiol. 43(4): 826-831.

Shoda, M. and Ishikawa, Y., 2014. Heterotrophic nitrification and aerobic denitrification of high-strength ammonium in anaerobically digested sludge by Alcaligenes faecalis strain No. 4. J. Biosci. Bioeng. 117(6): 737-741.

Song, Y. C., Kwon, S. J., \& Woo, J. H. 2004. Mesophilic and thermophilic temperature co-phase anaerobic digestion compared with single-stage mesophilic-and thermophilic digestion of sewage sludge. Water res., 38(7), $1653-1662$. 
610 Tong, J., Liu, J., Zheng, X., Zhang, J., Ni, X., Chen, M. and Wei, Y., 2016. Fate of

611 antibiotic resistance bacteria and genes during enhanced anaerobic digestion of 612 sewage sludge by microwave pretreatment. Bioresour. Technol. 217: 37-43.

613 Tong, J., Lu, X. T., Zhang, J. Y., Sui, Q. W., Wang, R., Chen, M. X. and Wei, Y. S., 614 2017. Occurrence of antibiotic resistance genes and mobile genetic elements in 615 enterococci and genomic DNA during anaerobic digestion of pharmaceutical 616 waste sludge with different pretreatments. Bioresour. Technol. 235: 316-324.

617 Tremblay, C. L., Letellier, A., Quessy, S., Boulianne, M., Daignault, D. and 618 Archambault, M., 2011. Multiple-Antibiotic resistance of Enterococcus faecalis 619 and Enterococcus faecium from cecal contents in broiler chicken and turkey 620 flocks slaughtered in Canada and plasmid colocalization of tet $\mathrm{O}$ and ermB genes. $621 \quad$ J. Food Prot. 74(10): 1639-1648.

622 Wu, B., Wang, X., Deng, Y. Y., He, X. L., Li, Z. W., 2016. Adaption of microbial 623 community during the start-up stage of a thermophilic anaerobic digester treating 624 food waste. Biosci. Biotechnol. Biochem. 80(10): 2025-2032.

625 Wu, Y., Cui, E., Zuo, Y., Cheng, W., Rensing, C. and Chen, H., 2016. Influence of 626 two-phase anaerobic digestion on fate of selected antibiotic resistance genes and class I integrons in municipal wastewater sludge. Bioresour. Technol. 211:

629 Yuan, Q. B., Guo, M. T. and Yang, J., 2015. The sludge loading rate regulates the 630 growth and release of heterotrophic bacteria resistant to six types of antibiotics in 631 wastewater activated sludge. Environ. Sci. Process Impacts. 17(1): 206-212. 
632 Yi, J., Dong, B., Jin, J. and Dai, X. H., 2014. Effect of increasing total solids contents

633 on anaerobic digestion of food waste under mesophilic conditions: performance $634 \quad$ and microbial characteristics analysis. PloS one, 9(7): e102548.

635 Zhang, J. Y., Chen, M. X., Sui, Q. W., Tong, J., Jiang, C., Lu, X. T., Zhang, Y. X. and 636 Wei, Y. S., 2016. Impacts of addition of natural zeolite or a nitrification inhibitor 637 on antibiotic resistance genes during sludge composting. Water Res. 91: 339-349.

638 Zhang, J. Y., Lv, C., Tong, J., Liu, J. W., Liu, J. B., Yu, D. W., Wang, Y. W., Chen, M. 639 X. and Wei, Y. S., 2016. Optimization and microbial community analysis of 640 anaerobic co-digestion of food waste and sewage sludge based on microwave 641 pretreatment. Bioresour. Technol. 200: 253-261.

642 Zhang, J. Y., Sui, Q. W., Tong, J., Zhong, H., Wang, Y. W., Chen, M. X., Wei, Y. S., 643 2018. Soil types influence the fate of antibiotic-resistant bacteria and antibiotic 644 resistance genes following the land application of sludge composts [J]. Environ. $645 \quad$ Int. 2018, 118:34-43.

646 Zhang, T., Shao, M. F. and Ye, L., 2012. 454 Pyrosequencing reveals bacterial 647 diversity of activated sludge from 14 sewage treatment plants. ISME Journal. 648 6(6): $1137-1147$.

649 Zhang, T., Yang, Y. and Pruden, A., 2015. Effect of temperature on removal of 650 antibiotic resistance genes by anaerobic digestion of activated sludge revealed by 651 metagenomic approach. Appl. Microbiol. Biotechnol. 99(18): 7771-7779.

652 Zheng, J., Gao, R. X., Wei, Y. Y., Chen, T., Fan, J. Q., Zhou, Z. C., Makimilua, T. B., 653 Jiao, Y. N. and Chen, H., 2017. High-throughput profiling and analysis of 
654 antibiotic resistance genes in East Tiaoxi River, China. Environ. Pollut. 230: $655 \quad 648-654$.

656 Zhu, P., Chen, D. J., Liu, W. B., Zhang, J. B., Shao, L., Li, J. A. and Chu, J., 2014.

657 Hydroxylation and hydrolysis: Two main metabolic ways of spiramycin I in 658 anaerobic digestion. Bioresour. Technol. 153: 95-100.

659 Zuo, Z., Wu, S., Zhang, W. Q., Dong, R. J., 2013. Effects of organic loading rate and 660 effluent recirculation on the performance of two-stage anaerobic digestion of 661 vegetable waste. Bioresour. Technol. 146: 556-561. 
663 Table 1 Correlation analysis between absolute abundance of ARGs, sludge 664 characteristics, MGEs, bacterial diversity and major bacterial genera (green: $p<0.05$; 665 pink: $p<0.01)$.

666 Table 2 Multiple linear regression models.

667 
668 Table 1 Correlation analysis between absolute abundance of ARGs, sludge

669 characteristics, MGEs, bacterial diversity and major bacterial genera (green: $p<0.05$;

670 pink: $p<0.01)$

\begin{tabular}{|l|c|c|c|c|c|c|c|c|c|}
\hline $\begin{array}{l}\text { Correlation } \\
\text { coefficient }\end{array}$ & ere $\mathrm{A}$ & erm $\mathrm{B}$ & erm $\mathrm{F}$ & erm $\mathrm{X}$ & mef $\mathrm{A} / \mathrm{E}$ & $m p h \mathrm{~B}$ & tet $\mathrm{M}$ & tetO & $\begin{array}{c}\text { Total } \\
\text { ARGs }\end{array}$ \\
\hline sCOD & -0.860 & -0.727 & -0.767 & -0.666 & -0.552 & 0.517 & -0.580 & -0.154 & -0.832 \\
\hline Polysaccharides & -0.818 & -0.755 & -0.823 & -0.746 & -0.413 & 0.49 & -0.462 & -0.049 & -0.79 \\
\hline Protein & -0.874 & -0.699 & -0.711 & -0.651 & -0.566 & 0.524 & -0.566 & -0.161 & -0.818 \\
\hline ALK & 0.469 & 0.098 & 0.392 & 0.07 & 0.804 & -0.608 & 0.916 & 0.559 & 0.559 \\
\hline Shannon index & 0.580 & 0.322 & 0.680 & 0.48 & 0.245 & -0.65 & 0.343 & -0.105 & 0.455 \\
\hline Pielou index & 0.552 & 0.406 & 0.634 & 0.602 & 0.189 & -0.545 & 0.252 & -0.224 & 0.448 \\
\hline intI1 & 0.161 & 0.615 & 0.284 & 0.718 & -0.084 & 0.399 & -0.035 & -0.399 & 0.315 \\
\hline ISCR1 & 0.795 & 0.697 & 0.561 & 0.725 & 0.462 & -0.329 & 0.417 & -0.018 & 0.729 \\
\hline Tn916/1545 & -0.091 & -0.629 & -0.14 & -0.732 & 0.021 & -0.455 & 0.063 & 0.594 & -0.252 \\
\hline Brevundimonas & -0.320 & 0.109 & -0.364 & 0.082 & -0.356 & 0.637 & -0.449 & -0.09 & -0.191 \\
\hline Comamonas & -0.195 & -0.487 & -0.468 & -0.58 & 0.004 & 0.103 & 0.06 & 0.54 & -0.199 \\
\hline Longilinea & 0.431 & -0.141 & 0.375 & -0.002 & 0.343 & -0.76 & 0.396 & 0.117 & 0.198 \\
\hline Smithella & 0.347 & -0.214 & 0.244 & -0.158 & 0.410 & -0.581 & 0.515 & 0.221 & 0.193 \\
\hline Paludibacter & 0.382 & 0.112 & 0.612 & 0.053 & 0.399 & -0.427 & 0.641 & 0.263 & 0.403 \\
\hline Geobacter & 0.246 & 0.593 & 0.216 & 0.429 & 0.200 & 0.088 & 0.074 & -0.333 & 0.326 \\
\hline $\begin{array}{l}\text { Candidatus } \\
\text { Cloacamonas }\end{array}$ & 0.316 & -0.116 & 0.425 & 0.083 & 0.389 & -0.596 & 0.575 & 0.221 & 0.267 \\
\hline Crocinitomix & 0.580 & 0.021 & 0.292 & -0.088 & 0.516 & -0.636 & 0.548 & 0.375 & 0.399 \\
\hline Methanolinea & 0.465 & -0.163 & 0.357 & -0.044 & 0.429 & -0.777 & 0.501 & 0.305 & 0.265 \\
\hline Sulfuricurvum & 0.369 & -0.026 & 0.397 & -0.113 & 0.467 & -0.475 & 0.641 & 0.385 & 0.373 \\
\hline Simplicispira & 0.591 & 0.591 & 0.369 & 0.474 & 0.263 & -0.145 & 0.263 & 0.134 & 0.591 \\
\hline Tissierella & -0.112 & 0.407 & -0.112 & 0.405 & -0.056 & 0.614 & -0.100 & -0.383 & 0.080 \\
\hline Sphingobacterium & -0.624 & -0.266 & -0.763 & -0.188 & -0.349 & 0.643 & -0.486 & -0.055 & -0.459 \\
\hline
\end{tabular}


671 Table 2 Multiple linear regression models.

\begin{tabular}{|c|c|c|c|c|c|}
\hline \multirow{2}{*}{$\begin{array}{l}\text { Absolute abundance } \\
\text { of ARG } \\
\left(\log \text { copies } \cdot \mathrm{g}^{-1}\right)\end{array}$} & \multirow{2}{*}{ Multiple linear regression models } & \multirow{2}{*}{$p$ Value $^{\mathrm{a}}$} & \multirow{2}{*}{$\begin{array}{c}\text { Interpretation of } \\
\text { models in variation of } \\
\text { ARG }(\%)\end{array}$} & \multicolumn{2}{|c|}{ Interpretation of factors in variation of ARG (\%) } \\
\hline & & & & Factors & Interpretation $(\%)$ \\
\hline \multirow[t]{2}{*}{ ere $\mathrm{A}$} & ere $\mathrm{A}=1.021+0.0005$ Chao $1+0.732$ ISCRI & 0.000 & 86.1 & Chao1 & 78.8 \\
\hline & & & & Chao1, ISCRI & 86.1 \\
\hline erm $\mathrm{B}$ & erm $\mathrm{B}=0.462+0.950$ int 11 & 0.000 & 76.3 & intI1 & 76.3 \\
\hline erm $\mathrm{F}$ & erm $\mathrm{F}=4.339+0.637$ Shannon & 0.000 & 80.0 & Shannon & 80.0 \\
\hline \multirow[t]{3}{*}{ ermX } & erm $\mathrm{X}=-0.867+0.725$ int $I 1+6.415$ Pielou- 0.265 coord 4 & 0.000 & 85.8 & intI1 & 50.3 \\
\hline & & & & int 1 , Pielou & 78.7 \\
\hline & & & & int $I 1$, Pielou, coord 4 & 85.8 \\
\hline \multirow[t]{2}{*}{$m e f \mathrm{~A} / \mathrm{E}$} & $m e f \mathrm{~A} / \mathrm{E}=2.668+0.001 \mathrm{ALK}+0.460$ intI 1 & 0.001 & 76.1 & ALK & 60.3 \\
\hline & & & & ALK, intI1 & 76.1 \\
\hline$m p h \mathrm{~B}$ & $m p h \mathrm{~B}=15.227-0.728 \operatorname{Tn} 916 / 1545$ & 0. & 59.7 & $\operatorname{Tn} 916 / 1545$ & 59.7 \\
\hline \multirow[t]{2}{*}{$\operatorname{tet} \mathrm{M}$} & tet $\mathrm{M}=8.189+0.0005 \mathrm{ALK}+9.192 \times 10^{-5}$ Chao 1 & 0.000 & 88.1 & ALK & 82.6 \\
\hline & & & & ALK, Chao1 & 88.1 \\
\hline \multirow[t]{3}{*}{ tet $\mathrm{O}$} & tet $\mathrm{O}=10.420+0.001$ ALK-4.870 Pielou+0.355 Coord 5 & 0.000 & 88.3 & ALK & 27.5 \\
\hline & & & & ALK, Pielou & 51.2 \\
\hline & & & & ALK, Pielou, coord5 & 88.3 \\
\hline total ARGs & total ARGs $=32.391+4.892$ ISCRI & 0.001 & 66.4 & ISCR1 & 66.4 \\
\hline
\end{tabular}

672 Note: $a-p$ value from the F-test. A $p$ value $<0.05$ means that the multiple linear regression model is significant at $95 \%$ and linear relationships are not rejected. 
674 Figure 1 Scheme of the sludge treatment methods.

675 Figure 2 Variation of sludge characteristics during sludge treatment.

676 Figure 3 Variation in bacterial diversity during the sludge treatments.

677 Figure 4 Bacterial community succession during sludge treatment. (a) Relative

678 abundance of bacterial at phylum level; and (b) Heat map of the top 10 genera in each

679 sludge sample based on relative abundance ( $\log 2$ transformed).

680 Figure 5 Evolution of the microbial community during sludge treatment by principal

681 component analysis (PCA) based on the top 10 abundant genera of each sample.

682 Red solid circles: samples name; blue arrows: the top 10 abundant genera of each

683 sample. Abbreviations are as follows: Raw, raw sludge; MW, microwave pretreated

684 sludge; $\mathrm{TH}$, thermal hydrolysis pretreatment sludge; $\mathrm{O}_{3}$, ozone pretreated sludge; Raw

685 ADin, inlet sludge of $\mathrm{AD}$ without pretreatment; Raw ADout, digested sludge of $\mathrm{AD}$

686 without pretreatment; MW ADin, inlet sludge of AD with microwave pretreatment;

687 MW ADout, digested sludge of AD with microwave pretreatment; TH ADin, inlet

688 sludge of AD with thermal hydrolysis pretreatment; TH ADout, digested sludge of AD

689 with thermal hydrolysis pretreatment; $\mathrm{O}_{3} \mathrm{ADin}$, inlet sludge of $\mathrm{AD}$ with ozone

690 pretreatment; $\mathrm{O}_{3}$ ADout, digested sludge of $\mathrm{AD}$ with ozone pretreatment; Number

691 1-61 expressed the 61 abundant genera (genera names shown in Table S3) of 36 692 samples.

693 Figure 6 Removal of ARGs and MGEs during sludge pretreatment and AD.

694 Figure 7 Procrustes analysis between ARG abundance (PCoA based on Bray-Curtis) 
695 and bacterial composition (PCoA based on Bray-Curtis) for sludge pretreatment and 696 AD. Abbreviations are as defined in Figure 5. 

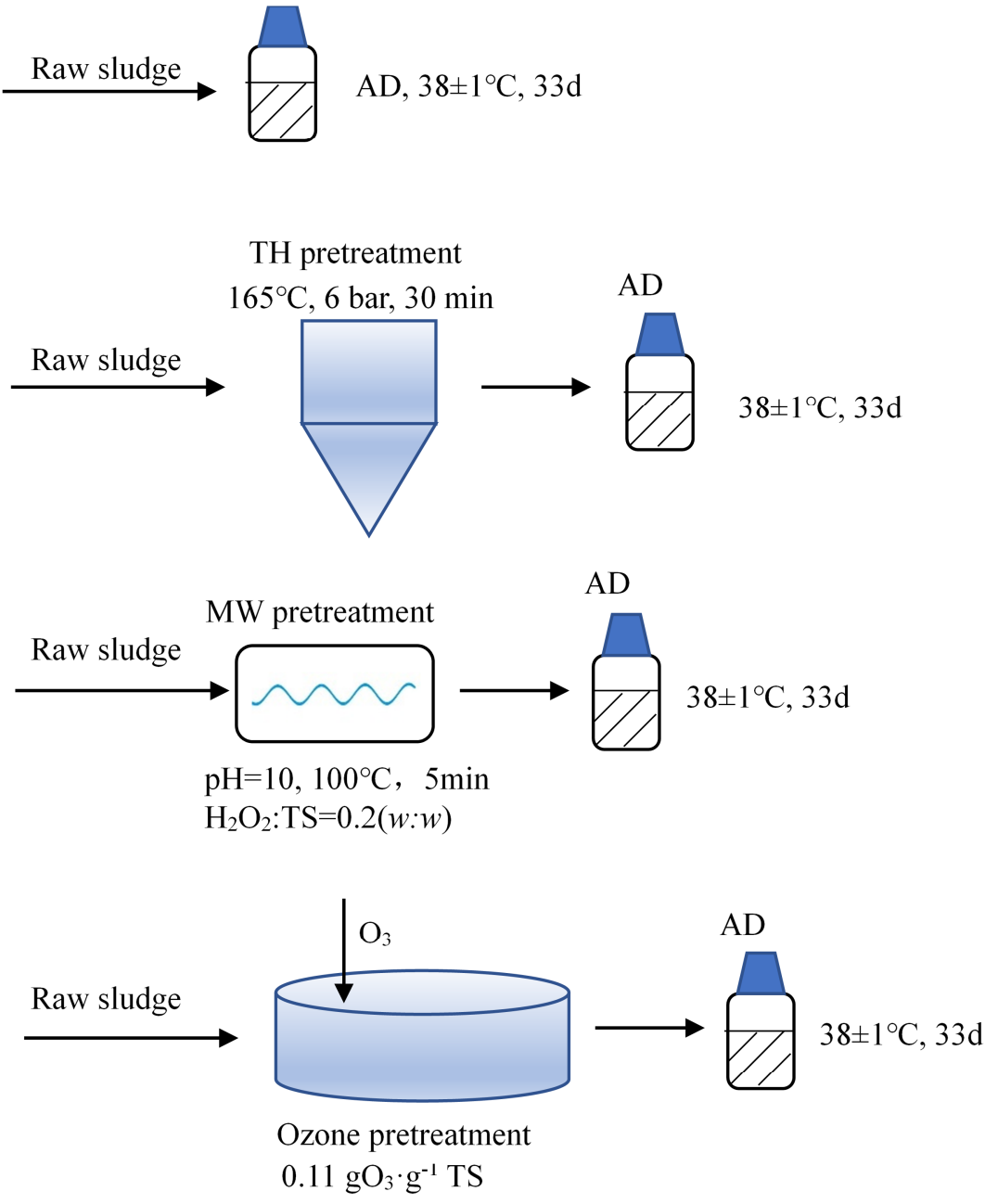

Figure 1 Scheme of the sludge treatment methods. 


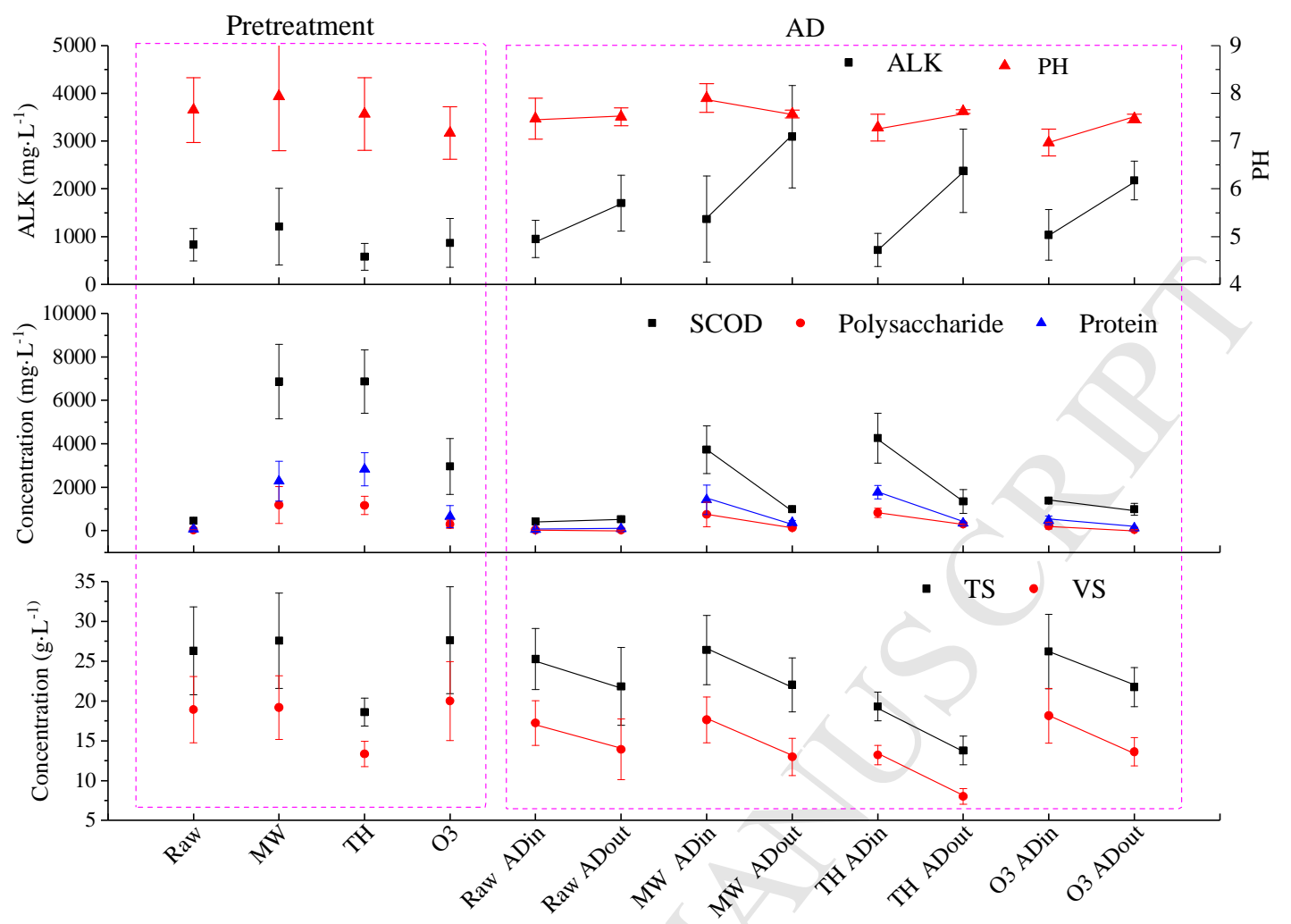

700

Figure 2 Variation of sludge characteristics during sludge treatment. 


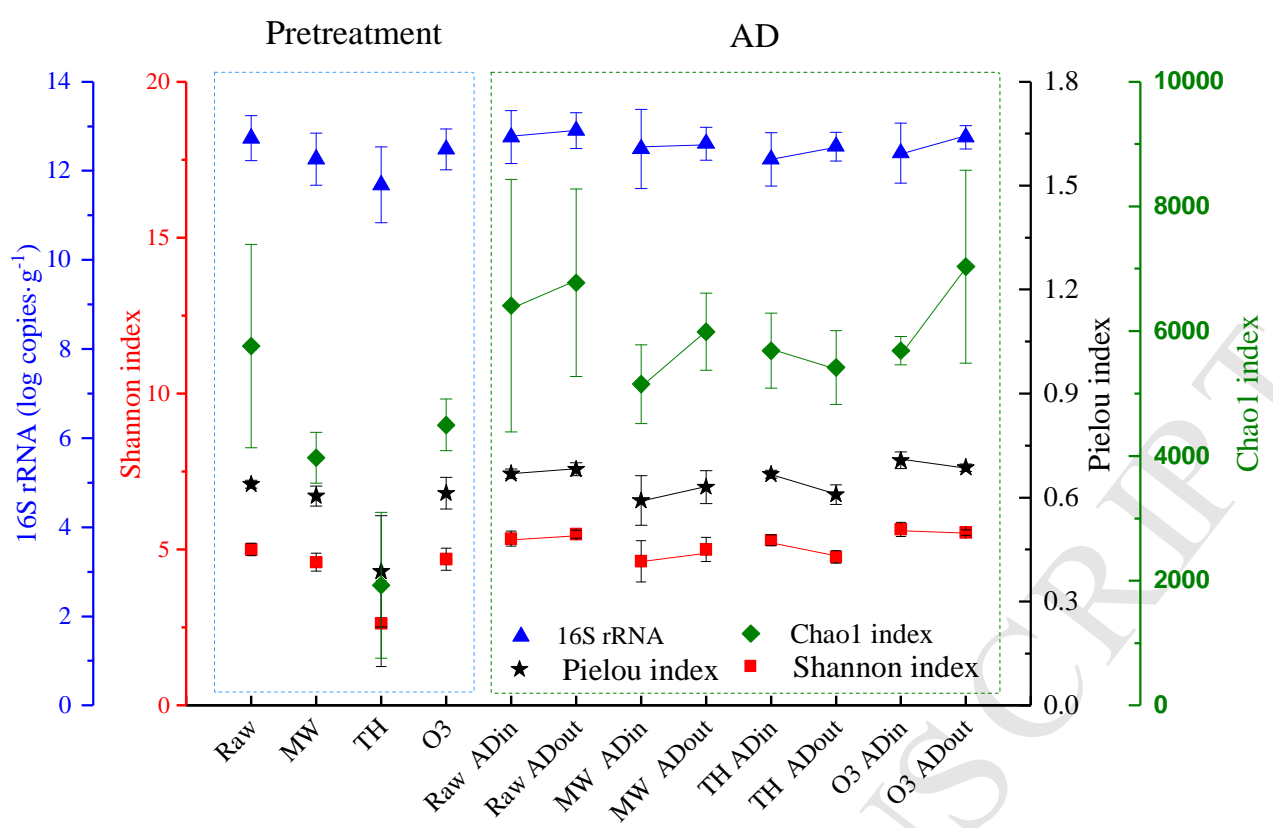

702

Figure 3 Variation in bacterial diversity during the sludge treatments. 


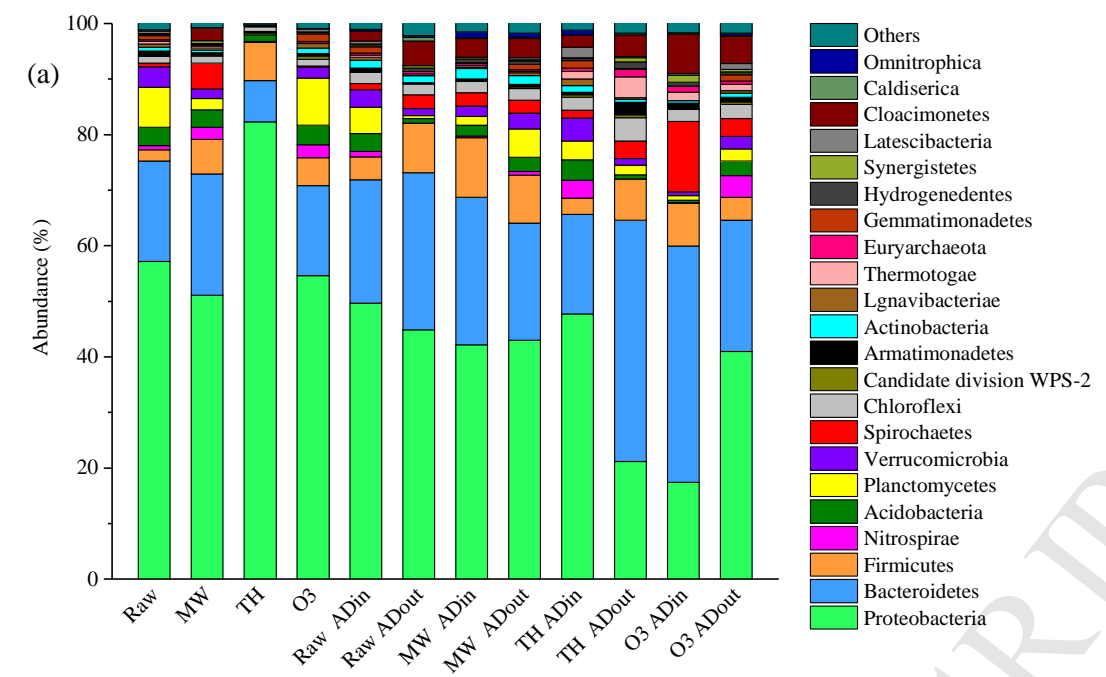

(b)
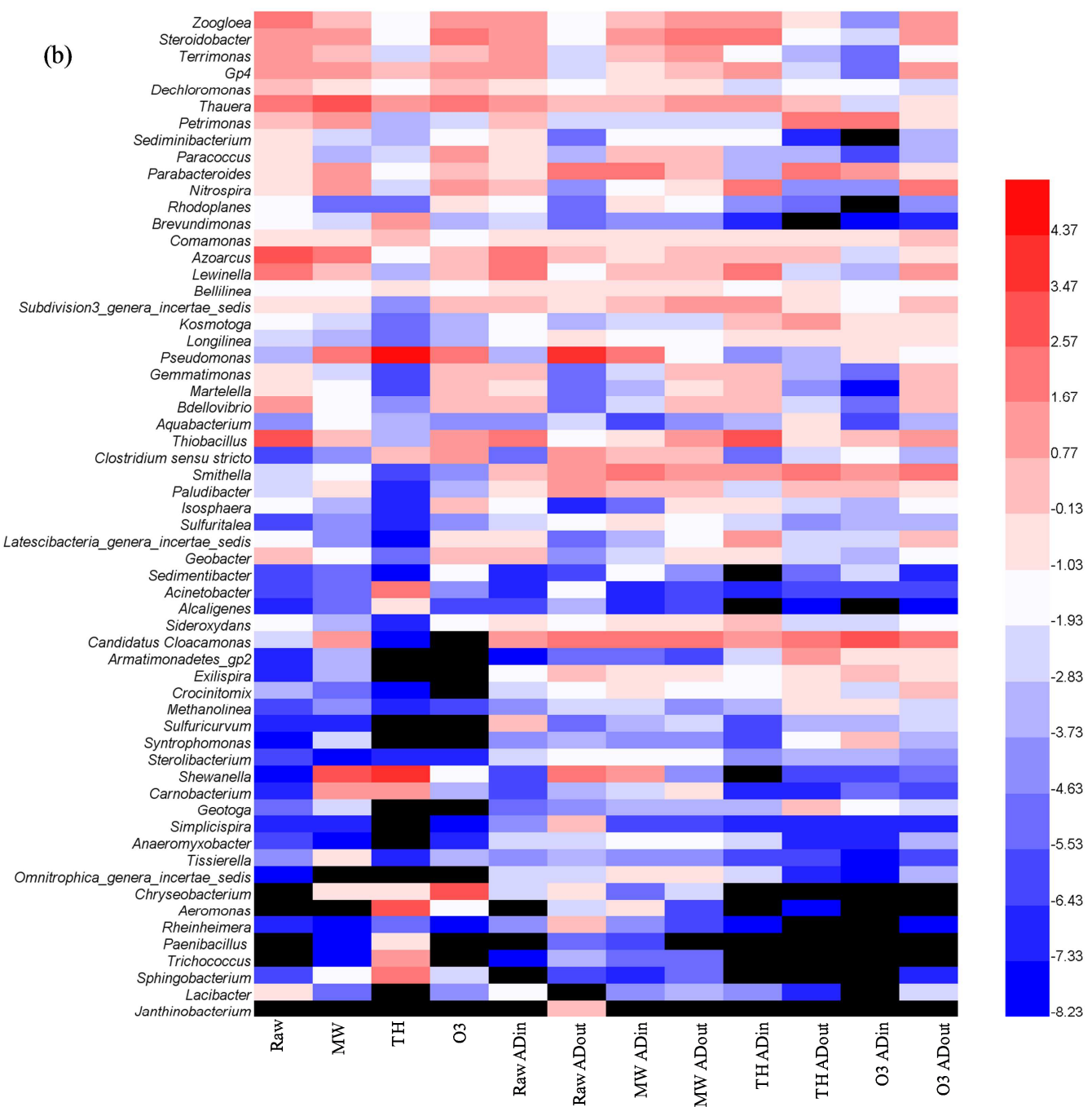

706 Figure 4 Bacterial community succession during sludge treatment. (a) Relative

707 abundance of bacterial at phylum level; and (b) Heat map of the top 10 genera in each

708 sludge sample based on relative abundance ( $\log 2$ transformed). 


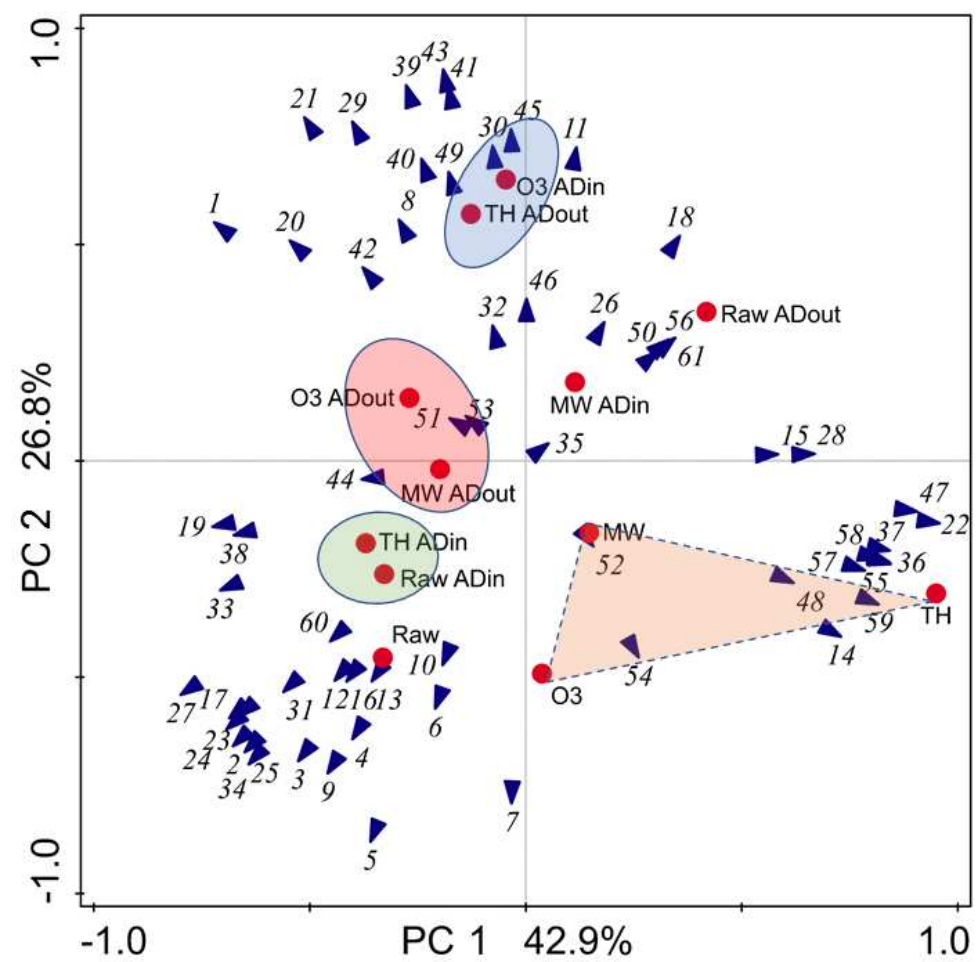

710 Figure 5 Evolution of the microbial community during sludge treatment by principal

711 component analysis (PCA) based on the top 10 abundant genera of each sample.

712 Red solid circles: samples name; blue arrows: the top 10 abundant genera of each

713 sample. Abbreviations are as follows: Raw, raw sludge; MW, microwave pretreated

714 sludge; $\mathrm{TH}$, thermal hydrolysis pretreatment sludge; $\mathrm{O}_{3}$, ozone pretreated sludge; Raw

715 ADin, inlet sludge of AD without pretreatment; Raw ADout, digested sludge of $\mathrm{AD}$

716 without pretreatment; MW ADin, inlet sludge of AD with microwave pretreatment;

717 MW ADout, digested sludge of AD with microwave pretreatment; TH ADin, inlet

718 sludge of AD with thermal hydrolysis pretreatment; TH ADout, digested sludge of AD

719 with thermal hydrolysis pretreatment; $\mathrm{O}_{3}$ ADin, inlet sludge of $\mathrm{AD}$ with ozone

720 pretreatment; $\mathrm{O}_{3}$ ADout, digested sludge of $\mathrm{AD}$ with ozone pretreatment; Number

721 1-61 expressed the 61 abundant genera (genera names shown in Table S3) of 36 
722 samples.

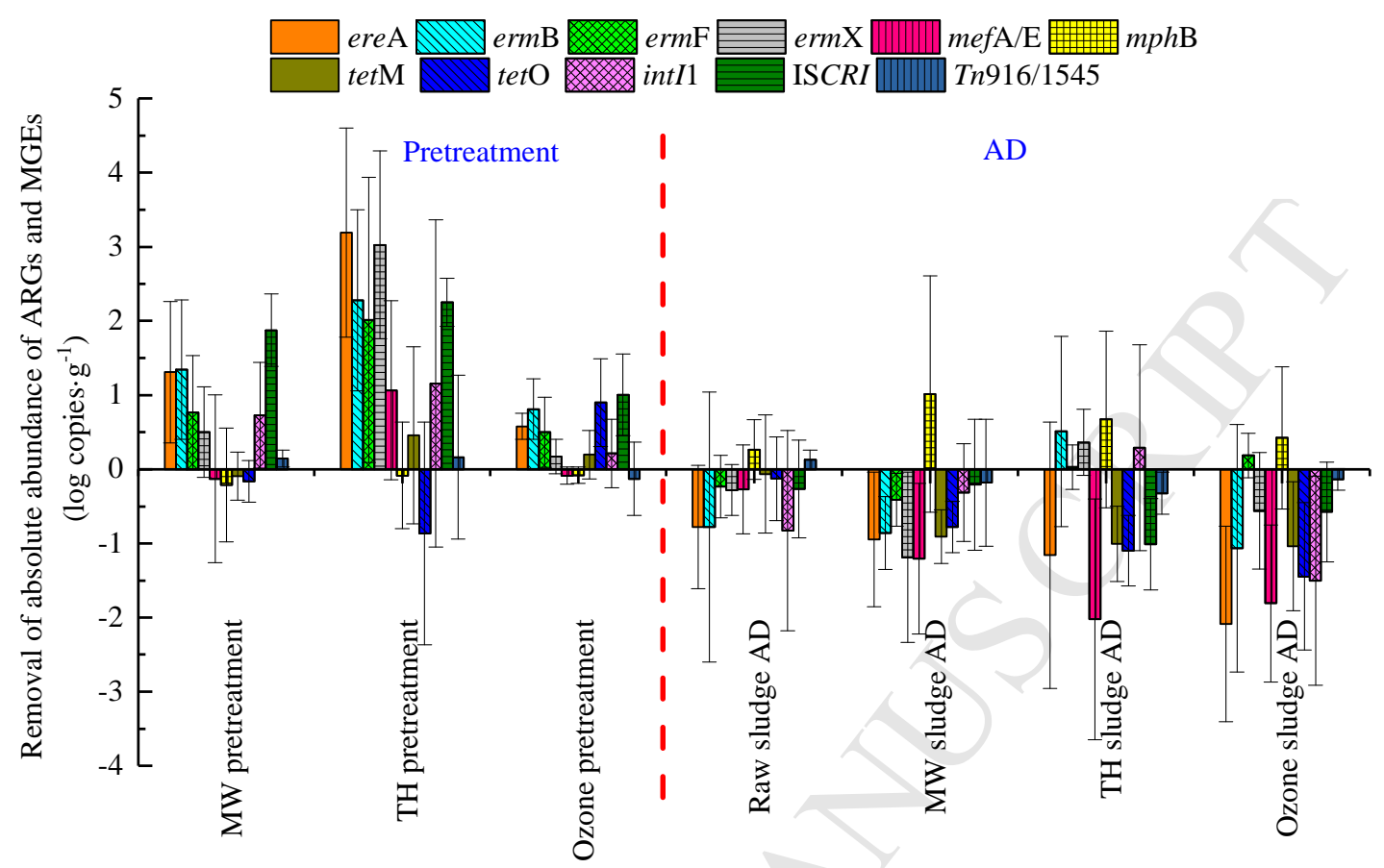

723

724 Figure 6 Removal of ARGs and MGEs during sludge pretreatment and AD. 


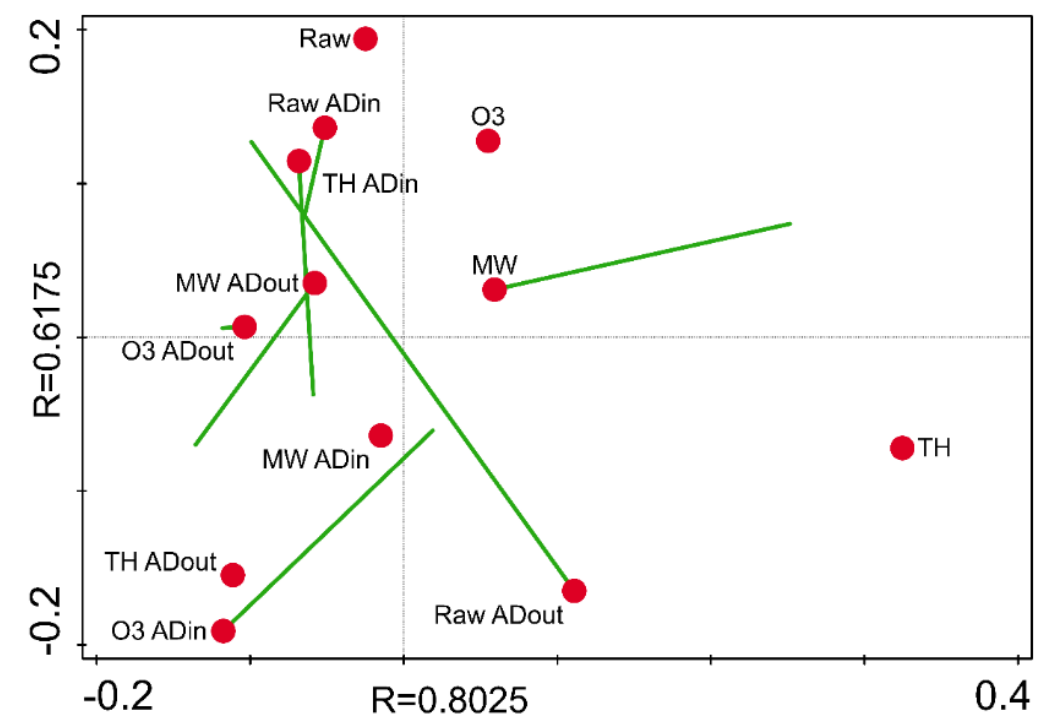

725

726 Figure 7 Procrustes analysis between ARG abundance (PCoA based on Bray-Curtis)

727 and bacterial composition (PCoA based on Bray-Curtis) for sludge pretreatment and

728 AD. Abbreviations are as defined in Figure 5. 


\section{Highlights}

- Factors impact on ARGs during pharmaceutical sludge treatment were studied.

- Multiple linear regression was used to assess the importance of factors on ARGs.

- Alkalinity showed more influence on ARGs than other sludge features.

- Bacterial diversity rather than community composition affected ARGs.

- Interaction effect and contributions of each factor on ARGs were elucidated. 